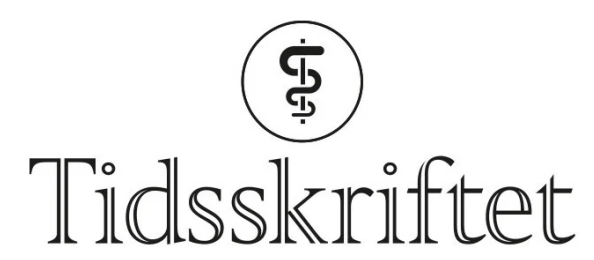

DEN NORSKE LEGEFORENING

\title{
UV-A-stråling og melanomer
}

\author{
BREV TIL REDAKTØREN
}

\section{ASTA JUZENIENE}

Oslo universitetssykehus

\section{JOHAN MOAN}

Oslo universitetssykehus

og

Fysisk institutt

Universitetet i Oslo

I nr. 18/2010 omtalte Veierød og medarbeidere sammenhengen mellom solarier og hudkreft (1). Vi har i 30 år hevdet at soling, særlig bråsoling, er hovedårsaken til hudkreft og vist det ved nord-sør-gradienter i insidens, kroppsfordeling osv. (ㅁ). Dette er nå allment akseptert.

For melanomer er epidemiologien mer komplisert $(\underline{2}, 3)$. Utearbeidende bønder og fiskere har forbausende lav risiko. Ikke-melanomer skyldes mest UV-B (280-315 nm), mens vi trodde at melanomer kunne forårsakes av både UV-B og UV-A (315-40o nm) (ㅁ), og at UV-A var særlig melanominduserende (3). Setlows banebrytende fiskeeksperimenter fra 1993 ( som bekreftet UV-A-strålingens melanominduserende effekt) kan imidlertid være feil (4). Melanomer kan induseres i transgene mus og Monodelphis domestica ved UV-B, men ikke

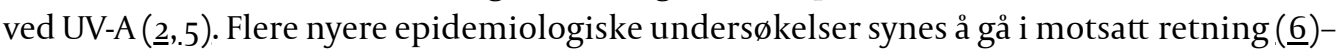
(므).

Bruk av solarier ( som gir relativt mye UV-A) synes å gi økt risiko for melanom. Tidligere epidemiologiske studier, utført med sterkere solarier enn nå, viste ingen klar melanomrisiko (9.). Vi får imidlertid tro at de nyere unders $\emptyset$ kelsene er best. Nye dyrefors $\emptyset \mathrm{k}$ viser altså at UV-A ikke gir melanomer, mens nye epidemiologiske solariestudier antyder det motsatte $(\underline{1}, \underline{6})-(\underline{8})$. Problemet er altså ikke løst, og vi må vente på ny forskning, som vil være av stor helsemessig betydning, siden både sol og solarier gir mye D-vitaminer (5), solen bare om sommeren. D-vitaminets mange helsevirkninger er nå lærebokstoff.

\section{LITTERATUR}

1. Veierød MB, Nilsen LT, Robsahm TE. Solarier, vitamin D og hudkreft. Tidsskr Nor Legeforen 2010; 130: 1818-21.

2. Moan J, Porojnicu AC, Dahlback A. Ultraviolet radiation and malignant melanoma. Adv Exp Med Biol 2008; 624:104-16. 
3. Moan J, Dahlback A, Setlow RB. Epidemiological support for an hypothesis for melanoma induction indicating a role for UVA radiation. Photochem Photobiol 1999; 70: 243-7.

4. Mitchell DL, Fernandez AA, Nairn RS et al. Ultraviolet A does not induce melanomas in a Xiphophorus hybrid fish model. Proc Natl Acad Sci U S A 2010; 107: 9329-34.

5. Cicarma E, Porojnicu AC, Lagunova $Z$ et al. Sun and sun beds: inducers of vitamin D and skin cancer. Anticancer Res 2009; 29:3495-500.

6. Veierød MB, Adami HO, Lund E et al. Sun and solarium exposure and melanoma risk: effects of age, pigmentary characteristics, and nevi. Cancer Epidemiol Biomarkers Prev 2010; 19: 111-20.

7. Lazovich D, Vogel RI, Berwick M et al. Indoor tanning and risk of melanoma: a case-control study in a highly exposed population. Cancer Epidemiol Biomarkers Prev 2010; 19:1557-68.

8. Autier P, Doré JF, Eggermont AM et al. Epidemiological evidence that UVA radiation is involved in the genesis of cutaneous melanoma. Curr Opin Oncol 2010; doi: 10.1097/CCO.obo13e3283436e5d.

9. International Agency for Research on Cancer. The association of use of sunbeds with cutaneous malignant melanoma and other skin cancers: A systematic review. Int J Cancer 2007; 120: 1116-22.

Publisert: 18. februar 2011. Tidsskr Nor Legeforen. DOI: 10.4045/tidsskr.10.1124

(C) Tidsskrift for Den norske legeforening 2023. Lastet ned fra tidsskriftet.no 26. april 2023. 